\title{
Printed Circuit Board Device
}

National Cancer Institute

\section{Source}

National Cancer Institute. Printed Circuit Board Device. NCI Thesaurus. Code C50097.

A circuit board that has connections that are preapplied, usually added using photo-resist and acid etching techniques. 